Original Article

\title{
Effects of concentric and eccentric control exercise on gross motor function and balance ability of paretic leg in children with spastic hemiplegia
}

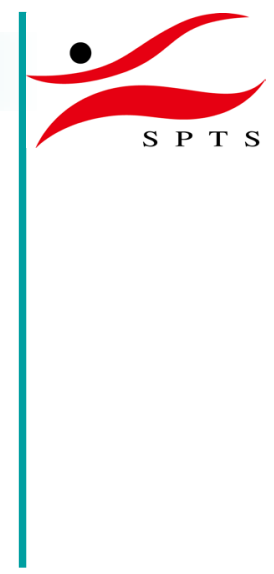

\author{
Su-Ik Park, PT, MS ${ }^{1)}$, Mi-Sun Kim, PT, MS²), Jong-Duk Chol, PT, PhD³** \\ 1) Department of Physical Therapy, Graduate School of Health and Medicine, Daejeon University, \\ Republic of Korea \\ 2) Department of Physical Therapy, Graduate School, Daejeon University, Republic of Korea \\ 3) Department of Physical Therapy, College of Health and Medical Science, Daejeon University: 62 \\ Daehak-ro, Dong-gu, Daejeon 300-716, Republic of Korea
}

\begin{abstract}
Purpose] This study examines the effect of concentric and eccentric control training of the paretic leg on balance and gross motor function in children with spastic hemiplegia. [Subjects and Methods] Thirty children with spastic hemiplegia were randomly divided into experimental and control groups. In the experimental group, $20 \mathrm{~min}$ of neurodevelopmental therapy and $20 \mathrm{~min}$ of concentric and eccentric control exercise were applied to the paretic leg. In the control group, 40 min of neurodevelopmental therapy was applied. The Pediatric Balance Scale test and standing and gait items of the Gross Motor Function Measure were evaluated before and after intervention. [Results] In the experimental group, Gross Motor Function Measure and Pediatric Balance Scale scores statistically significantly increased after the intervention. The control group showed no statistically significant difference in either score after the intervention. [Conclusion] Concentric and eccentric control exercise therapy in children with spastic hemiplegia can be effective in improving gross motor function and balance ability, and can be used to solve functional problems in a paretic leg.

Key words: Cerebral palsy, Gross motor function, Strength training
\end{abstract}

(This article was submitted Feb. 19, 2016, and was accepted Apr. 7, 2016)

\section{INTRODUCTION}

Children with spastic hemiplegia experience decreased balance ability and abnormal gait because of decreased weightbearing in the paretic $\operatorname{leg}^{1-3}$. Diminished motor ability in the paretic leg causes weakening of the quadriceps, ankle plantar flexors, and ankle dorsiflexors ${ }^{4}$ 5). To enhance balance and motor ability in the paretic leg in children with spastic hemiplegia, a therapeutic approach promoting weight-shifting to the paretic side and strengthening of paretic leg muscles is required ${ }^{4,6)}$.

Muscle-strength-enhancement exercise in children with cerebral palsy results in an increase in stride length and gait velocity, decreased crutch gait, and improvement in the Gross Motor Function Measure ${ }^{7}$. Brown et al. ${ }^{8)}$ reported that muscle strength of the ankle plantar flexors and dorsiflexors of the paretic leg in children with spastic hemiplegia was respectively $75 \%$ and $72 \%$ of that of the unaffected side. Horvat $\left.{ }^{9}\right)$ reported that muscle strength of knee extensors and flexors in the paretic leg in cases of spastic hemiplegia was respectively $42 \%$ and $52 \%$ of that of the unaffected side. Horvat ${ }^{9}$ applied a gradual resistance exercise program in children with spastic hemiplegia for 8 weeks and reported that knee flexor and extensor muscle strength increased $100 \%$ and $129 \%$, respectively. This suggests that knee-muscle-strength exercise is necessary to improve walking function in children with spastic hemiplegia; the benefits include gross motor function enhancement, faster walking,

*Corresponding author. Jong-Duk Choi (E-mail: choidew@dju.kr)

(C2016 The Society of Physical Therapy Science. Published by IPEC Inc.

This is an open-access article distributed under the terms of the Creative Commons Attribution Non-Commercial No Derivatives (by-nc-nd) License $<$ http://creativecommons.org/licenses/by-nc-nd/4.0/>. 
and increased energy efficiency after knee extensor training ${ }^{10)}$. Hwang ${ }^{11)}$ implemented eccentric muscle strength exercise for the paretic leg in patients with hemiplegia and reported improvement of muscle strength, cadence, gait velocity, and weight-bearing on the paretic side during walking.

Research on the positive impact of eccentric muscle strength exercise on daily life is ongoing. However, most studies involved muscle strength exercise in supine, prone, and sitting positions. Few studies have evaluated the impact of weightbearing muscle-strength-enhancement training of an independent and controlled paretic ankle and knee on balance ability and gross motor function. Hence, this study examined the effects of weight-shifting to a standing paretic leg and concentric and eccentric muscle strength exercise on balance and gross motor function in children with spastic hemiplegia.

\section{SUBJECTS AND METHODS}

Thirty children with spastic hemiplegia were randomly divided into experimental and control groups. The inclusion criteria were as follows: diagnosis of spastic hemiplegia, Gross Motor Function Classification System (GMFCS) level I-II and able to walk and jump ${ }^{12}$, modified mini-mental state examination score over $25^{13)}$, absence of vision or hearing deficits, and no medicine or surgery that affects balance. All protocols were approved by the University of Daejeon. Before participation, the procedures, risks, and benefits were explained to the participants, who gave informed consent. Participant rights were protected according to the guidelines of the University of Daejeon.

The Pediatric Balance Scale (PBS) and Gross Motor Function Measure (GMFM) were used in the study. The PBS can be applied in children with brain damage and consists of a total of 14 items in 3 domains, including sitting, standing, and changing of position. The highest score is 56 and a higher score indicates better standing balance ability ${ }^{14)}$. The GMFM measures the change in motor function in children $\left.{ }^{15}, 16\right)$. The participants performed 88 kinds of motions in 5 domains without assistance by the tester. Among the 5 domains, total scores in domain D (standing) and domain E (gait, running, and jumping) were compared in this study.

The duration of training was 4 weeks. In the experimental group, 20 min of neurodevelopmental therapy and 20 min of muscle-strength-enhancement training were applied to the paretic leg. In the control group, 40 min of neurodevelopmental therapy was applied. The method of concentric and eccentric muscle-strength-enhancement training for the paretic leg is as follows. A subject stands on a height-adjustable table where he/she is able to bear weight on the paretic leg while holding a stall bar with the upper limb on the paretic side. The subject pushes a ball back and forth on the ground using the non-paretic leg by controlling the ankle and knee joints of the paretic leg. The motion is repeated 10 times for one set followed by 1 min of rest. A total of 10 sets are performed.

General characteristics of the research subjects were examined by cross-tabulation analysis and independent t-tests using descriptive statistics. A paired t-test was used to compare differences before and after the experiment in each group. An independent t-test was used to compare differences before and after the experiment between the 2 groups. The Statistical Package for the Social Sciences for Windows, version 18.0 (SPSS, Chicago, IL, USA) was used for statistical analysis. A statistical significance level was set at $\alpha=0.05$ for all data (Table 1 ).

\section{RESULTS}

In the experimental group, PBS statistically significantly increased from 53.07 to 54.61 after training ( $<<0.05)$. Standing in GMFM statistically significantly increased from 94.47 to 95.85 after the intervention $(p<0.05)$. Gait, running and jumping in GMFM statistically significantly increased from 93.58 to 94.65 after the intervention $(\mathrm{p}<0.05)$ (Table 2).

\section{DISCUSSION}

Compared to normal children, even children with spastic cerebral palsy with a high functional level show leg muscle weakening $\left.{ }^{7}, 17\right)$. Geoffrey et al. ${ }^{18)}$ stated that the ankle plantar flexors are the weakest muscles. Horvat ${ }^{9)}$ reported that muscle strength in the paretic knee extensors and flexors was $42-52 \%$ of that on the unaffected side in hemiplegic children. Musclestrength-enhancement training is critical for functional improvement in children with spastic hemiplegia ${ }^{4}$. Hence, this study examined the effects of concentric and eccentric exercise control training on the paretic leg in children with spastic hemiplegia.

Damiano and $\mathrm{Abel}^{4)}$ reported that gross motor function and pediatric balance ability improved after leg-muscle-strengthenhancement training. Dodd et al. $\left.{ }^{19}\right)$ reported that GMFM, gait velocity, and walking upstairs improved in children with spastic diplegia after muscle-strength-enhancement training. Dodd et al. ${ }^{19)}$ applied muscle-strength-enhancement exercises to ankle plantar flexors and knee extensors in children with spastic diplegic cerebral palsy and reported improvement in items $\mathrm{D}$ and $\mathrm{E}$ in GMFM. In this study, control training of the paretic leg resulted in significant improvement in GMFM, similar to previous literature reports.

Shumway-Cook et al. ${ }^{20)}$ applied 5 days of intensive balance training in children with spastic hemiplegia and diplegia and reported significantly improved core stability. In this study, control training of the paretic leg caused significant improvement in balance ability in children. It is possible that control function and balance reaction improved due to stable muscle activity 
Table 1. Characteristics of study participants

\begin{tabular}{lcc}
\hline & $\begin{array}{c}\text { Experimental } \\
\text { group }(\mathrm{n}=15)\end{array}$ & $\begin{array}{c}\text { Control } \\
\text { group }(\mathrm{n}=15)\end{array}$ \\
\hline Gender & & \\
Male & $9(60.0)^{\mathrm{a}}$ & $10(66.7)$ \\
Female & $6(40.0)$ & $5(33.3)$ \\
GMFCS (L1/L2) & $11(73.3) / 4(26.7)$ & $60.1 \pm 12.3$ \\
Age $(\mathrm{yr})$ & $11.6 \pm 2.0^{\mathrm{b}}$ & $166.8 \pm 10.0$ \\
Height $(\mathrm{cm})$ & $123.1 \pm 14.0$ & $65.7 \pm 8.8$ \\
Weight $(\mathrm{kg})$ & $28.3 \pm 7.6$ & \\
\hline${ }^{\mathrm{a}} \mathrm{n}(\%) ;{ }^{\mathrm{b}}$ Mean \pm standard deviation; ${ }^{\mathrm{c}}$ GMFCS: Gross Motor Function Classification System
\end{tabular}

Table 2. A comparison of balance and Gross Motor Function before and after training

\begin{tabular}{llcc}
\hline & & $\begin{array}{c}\text { Experimental } \\
\text { group (n=15) }\end{array}$ & $\begin{array}{c}\text { Control } \\
\text { group (n=15) }\end{array}$ \\
\hline \multirow{2}{*}{ Balance (score) } & Pre-test & $53.1 \pm 3.1^{\mathrm{a}}$ & $52.1 \pm 2.5$ \\
& Post-test & $54.6 \pm 1.4^{*}$ & $52.4 \pm 2.4$ \\
Standing (score) & Pre-test & $94.5 \pm 3.1$ & $92.9 \pm 2.4$ \\
Walking, running and jumping & $95.9 \pm 2.5^{*}$ & $93.3 \pm 2.9$ \\
(score) & Post-test & $93.6 \pm 4.3$ & $91.1 \pm 3.6$ \\
& Pre-test & $94.7 \pm 3.9^{*}$ & $91.3 \pm 3.7$ \\
\hline
\end{tabular}

${ }^{a}$ Mean \pm standard deviation. ${ }^{*} \mathrm{p}<0.05$

of the hip, knee, and ankle joints through consistent full weight-bearing control in the paretic leg.

There are several limitations in this study. First, the sample size was small, and it is difficult to generalize the study results to all children with spastic hemiplegia. Second, because there is limited literature on weight-bearing muscle-strengthenhancement exercise in children with GMFCS level I-II, it was difficult to compare study results. Hence, research using a larger sample of children with spastic hemiplegia will be needed to determine the long-term effects of muscle strengthening on the paretic lower limb. Moreover, multidimensional analysis using appropriate assessment tools will be needed to validate the results of concentric and eccentric weight-bearing exercise.

Concentric and eccentric control exercise therapy in children with spastic hemiplegia can be used as a means to solve functional problems in a paretic leg.

\section{ACKNOWLEDGEMENT}

This research was supported by the Deajeon University research fund (2014).

\section{REFERENCES}

1) Bobath B: Adult Hemiplegia: Evaluation and treatment, 3rd ed. London: Heinemann Medical books, 1990, pp 359-365.

2) Dettmann MA, Linder MT, Sepic SB: Relationships among walking performance, postural stability, and functional assessments of the hemiplegic patient. Am J Phys Med, 1987, 66: 77-90. [Medline]

3) Wolfson L, Judge J, Whipple R, et al.: Strength is a major factor in balance, gait, and the occurrence of falls. J Gerontol A Bilo Sci Med Sci, 1995 , 50 : $64-67$.

4) Damiano DL, Abel MF: Functional outcomes of strength training in spastic cerebral palsy. Arch Phys Med Rehabil, 1998, 79: 119-125. [Medline] [CrossRef]

5) Ki KI, Choi JD, Cho HS: The effect of ground tilt on the lower extremity muscle activity of stroke patients performing squat exercises. J Phys Ther Sci, 2014, 26: 965-968. [Medline] [CrossRef]

6) Ki KI, Kim MS, Moon Y, et al.: Effects of auditory feedback during gait training on hemiplegic patients' weight bearing and dynamic balance ability. J Phys Ther Sci, 2015, 27: 1267-1269. [Medline] [CrossRef]

7) Damiano DL, Kelly LE, Vaughn CL: Effects of quadriceps strengthening on crouch gait in children with spastic cerebral palsy. Phys Ther, 1995 , 75 : 658-667. [Medline]

8) Brown JK, Rodda J, Walsh EG, et al.: Neurophysiology of lower-limb function in hemiplegic children. Dev Med Child Neurol, 1991, 33: 1037-1047. [Medline] [CrossRef]

9) Horvat M: Effects of a progressive resistance training program on an individual with spastic cerebral palsy. Am Correct Ther J, 1987, 41: 7-11. 
10) Kramer JF, MacPhail HE: Relationships among measures of walking efficiency, gross motor ability and isokinetic strength in adolescents with cerebral palsy. Pediatr Phys Ther, 1994, 6: 3-9. [CrossRef]

11) Hwang BY: The Bobath concept in adult neurology. Seoul: Seoul med-media, 2008, pp 24-25.

12) Kembhavi G, Darrah J, Magill-Evans J, et al.: Using the berg balance scale to distinguish balance abilities in children with cerebral palsy. Pediatr Phys Ther, 2002, 14: 92-99. [Medline] [CrossRef]

13) Park JH, Kwon YC: Standardization of Korean version of the Mini-Mental State examination (MMSE-K) for use in the elderly. Part II. Diagnostic validity. J Korea Neuropsychiatr Assoc, 1989, 28: 508-513.

14) Franjoine MR, Gunther JS, Taylor MJ: Pediatric balance scale: a modified version of the berg balance scale for the school-age child with mild to moderate motor impairment. Pediatr Phys Ther, 2003, 15: 114-128. [Medline] [CrossRef]

15) Russell DJ, Rosenbaum PL, Gowland C, et al.: Gross motor function measure manual, 2nd ed. Toronto: McMaster University, 1989 , pp 341-352.

16) Lee BH, Kim YM, Jeong GC: Mediating effects of the ICF domain of function and the gross motor function measure on the ICF domains of activity, and participation in children with cerebral palsy. J Phys Ther Sci, 2015, 27: 3059-3062. [Medline] [CrossRef]

17) Wiley ME, Damiano DL: Lower-extremity strength profiles in spastic cerebral palsy. Dev Med Child Neurol, 1998, 40: 100-107. [Medline] [CrossRef]

18) Elder GC, Kirk J, Stewart G, et al.: Contributing factors to muscle weakness in children with cerebral palsy. Dev Med Child Neurol, 2003, 45: 542-550. [Medline] [CrossRef]

19) Dodd KJ, Taylor NF, Graham HK: A randomized clinical trial of strength training in young people with cerebral palsy. Dev Med Child Neurol, 2003, 45: 652-657. [Medline] [CrossRef]

20) Shumway-Cook A, Hutchinson S, Kartin D, et al.: Effect of balance training on recovery of stability in children with cerebral palsy. Dev Med Child Neurol, 2003, 45: 591-602. [Medline] [CrossRef] 